\title{
High performance Ce-doped ZnO nanorods for sunlight-driven photocatalysis
}

\author{
Bilel Chouchene ${ }^{1}$, Tahar Ben Chaabane ${ }^{1}$, Lavinia Balan ${ }^{2}$, Emilien Girot $^{3}$, Kevin Mozet ${ }^{3}$, \\ Ghouti Medjahdi ${ }^{4}$ and Raphaël Schneider ${ }^{*}$
}

\section{Full Research Paper}

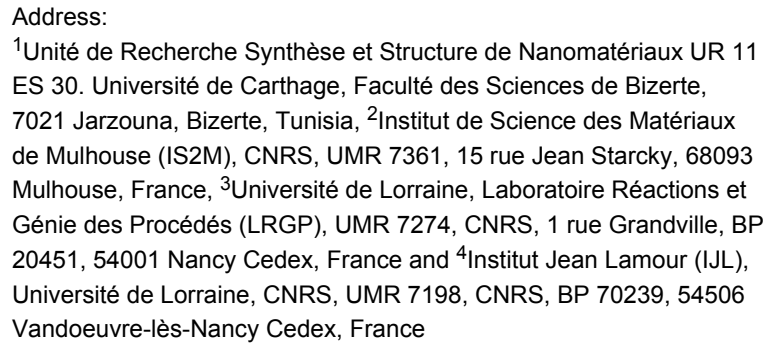

${ }^{1}$ Unité de Recherche Synthèse et Structure de Nanomatériaux UR 11 ES 30. Université de Carthage, Faculté des Sciences de Bizerte, 7021 Jarzouna, Bizerte, Tunisia, ${ }^{2}$ Institut de Science des Matériaux de Mulhouse (IS2M), CNRS, UMR 7361, 15 rue Jean Starcky, 68093 Mulhouse, France, ${ }^{3}$ Université de Lorraine, Laboratoire Réactions et Génie des Procédés (LRGP), UMR 7274, CNRS, 1 rue Grandville, BP 20451, 54001 Nancy Cedex, France and ${ }^{4}$ Institut Jean Lamour (IJL), Université de Lorraine, CNRS, UMR 7198, CNRS, BP 70239, 54506 Vandoeuvre-lès-Nancy Cedex, France

Email:

Raphaël Schneider ${ }^{*}$ - raphael.schneider@univ-lorraine.fr

* Corresponding author

Keywords:

Ce doping; photocatalysis; solvothermal synthesis; $\mathrm{ZnO}$ rods
Beilstein J. Nanotechnol. 2016, 7, 1338-1349.

doi:10.3762/bjnano.7.125

Received: 01 June 2016

Accepted: 03 September 2016

Published: 26 September 2016

Associate Editor: R. Xu

(c) 2016 Chouchene et al.; licensee Beilstein-Institut. License and terms: see end of document.

\begin{abstract}
$\mathrm{Ce}$-doped $\mathrm{ZnO}(\mathrm{ZnO}: \mathrm{Ce})$ nanorods have been prepared through a solvothermal method and the effects of Ce-doping on the structural, optical and electronic properties of $\mathrm{ZnO}$ rods were studied. ZnO:Ce rods were characterized by XRD, SEM, TEM, XPS, BET, DRS and Raman spectroscopy. 5\% Ce-doped $\mathrm{ZnO}$ rods with an average length of $130 \mathrm{~nm}$ and a diameter of $23 \mathrm{~nm}$ exhibit the highest photocatalytic activity for the degradation of the Orange II dye under solar light irradiation. The high photocatalytic activity is ascribed to the substantially enhanced light absorption in the visible region, to the high surface area of $\mathrm{ZnO}$ :Ce rods and to the effective electron-hole pair separation originating from Ce doping. The influence of various experimental parameters like the $\mathrm{pH}$, the presence of salts and of organic compounds was investigated and no marked detrimental effect on the photocatalytic activity was observed. Finally, recyclability experiments demonstrate that $\mathrm{ZnO}: \mathrm{Ce}$ rods are a stable solar-light photocatalyst.
\end{abstract}

\section{Introduction}

Due to the increasing pollution of water and air, there is a growing interest to find sustainable, efficient and cheap solutions to purify these media. In this context, semiconductor photocatalysis technology has been thoroughly studied since 1972 to solve environmental and energy challenges [1]. After absorp- tion of light with an adequate wavelength by the semiconductor, electrons $\left(\mathrm{e}^{-}\right)$are promoted from the valence band (VB) to the conduction band (CB) and holes $\left(\mathrm{h}^{+}\right)$generated in the VB to form electron-hole pairs. Most of these $\mathrm{e}^{-} / \mathrm{h}^{+}$pairs recombine and only a small percentage migrate to the surface of the photo- 
catalyst where they can be trapped by water and oxygen to generate hydroxyl ${ }^{\circ} \mathrm{OH}$ and superoxide $\mathrm{O}_{2}{ }^{\cdot-}$ radicals, respectively. These highly oxidizing species are responsible of the conversion of organic compounds into carbon dioxide, water, and inorganic salts.

Zinc oxide $(\mathrm{ZnO})$ is one of the most widely investigated semiconductor photocatalyst owing to its availability, weak toxicity, stability and relatively good resistance to photocorrosion [2-7]. However, to efficiently use $\mathrm{ZnO}$ in practice as an air and water decontamination agent, two drawbacks should be overcome. First, $\mathrm{ZnO}$ is a wide bandgap material $\left(E_{\mathrm{g}}=3.37 \mathrm{eV}\right.$ at room temperature) and can only be activated by UV light with a wavelength equal or lower than $385 \mathrm{~nm}$ to trigger the $\mathrm{e}^{-} / \mathrm{h}^{+}$separation. Second, $\mathrm{ZnO}$ suffers from a low photocatalytic efficiency due to the easy recombination of the photogenerated $\mathrm{e}^{-} / \mathrm{h}^{+}$pairs, which limits the diffusion of charge carriers from the bulk to the surface of $\mathrm{ZnO}$.

To shift $\mathrm{ZnO}$ absorption to the visible part of the solar spectrum and decrease charge recombination on the surface of the photocatalyst, doping of $\mathrm{ZnO}$ has been widely investigated in recent years [8-13]. Doping means introducing metal $(\mathrm{Cu}, \mathrm{Mn}$, $\mathrm{Co}, \mathrm{Al}, \ldots)$ or non-metal elements $(\mathrm{C}, \mathrm{N}, \mathrm{S}, \ldots)$ into the $\mathrm{ZnO}$ crystal lattice to change its properties. Doping of $\mathrm{ZnO}$ will increase the material defects and thus decrease $\mathrm{e}^{-} / \mathrm{h}^{+}$recombinations but also displace its adsorption to the visible range. In recent years, rare earth doping of $\mathrm{ZnO}$ has attracted significant attention, especially with cerium. $\mathrm{Ce}^{3+}$ possesses shielded $4 \mathrm{f}$ levels, which allow various well-defined narrow optical transitions between the spin-orbit levels and thus split the bandgap of $\mathrm{ZnO}$ into sub-gaps. For this reason, $\mathrm{Ce}^{3+}$ is generally doped or associated to $\mathrm{ZnO}$ to improve the luminescence efficiency by energy transfer processes and this topic is becoming an exciting area of research for developing electronic and optical applications like sensors, light-emitting phosphors or flat panel displays [14-27]. Due to the defects induced in the $\mathrm{ZnO}$ crystalline structure by Ce doping and the ability of this element to trap photogenerated charge carriers, Ce-doped $\mathrm{ZnO}(\mathrm{ZnO}: \mathrm{Ce})$ particles have also gained high interest for photocatalysis. Recently, a few $\mathrm{Ce}^{3+}$ - or $\mathrm{Ce}^{4+}$-doped $\mathrm{ZnO}$ photocatalyst containing large particles of spherical or needle morphology have been developed and their ability to degrade cyanide anions [28] or organic dyes [29-33] like methylene blue or methyl-orange has been demonstrated. The preparation of $\mathrm{Ce}-\mathrm{Cu}, \mathrm{Ce}-\mathrm{Pd}$ or $\mathrm{Ce}-\mathrm{Ag}$ co-doped photocatalysts to enhance the solar or the visible light catalytic response was also reported [34-36]. The synthesis of particles with well-defined properties is also of high importance to control the photocatalytic activity. Their optical, chemical and electronic properties are actually strongly dependent on shape, size, crystalline structure, defect concentra- tion, and surface area. Among the various $\mathrm{ZnO}$ nanostructures developed for photocatalytic applications, $\mathrm{ZnO}$ rods have attracted a high interest due to their stability, their large specific surface area that favor mass transfer and generate more reactive sites, and their weak sensibility to photocorrosion [37-48].

In this manuscript, a new solvothermal method for the preparation of small-sized $\mathrm{ZnO}$ :Ce rods with average length and diameter of ca. $130 \mathrm{~nm}$ and $23 \mathrm{~nm}$, respectively, is first described. The effects of Ce-doping on $\mathrm{ZnO}$ rods size and morphology and on their optical, electronic and photocatalytic properties have been investigated. Our results demonstrate that Ce-doping improves the optical absorption ability toward visible light wavelengths and thus the photocatalytic performances. $\mathrm{ZnO}$ :Ce rods allow the complete degradation of the Orange II dye in ca. $80 \mathrm{~min}$ under solar light irradiation. The possible mechanism of photodegradation is discussed. Finally, $\mathrm{ZnO}$ :Ce rods are highly stable, so that they can be reused up to five times without significant performance loss, which is a very attractive feature for practical photocatalytic applications.

\section{Results and Discussion Structural and optical characterizations of Ce-doped $\mathrm{ZnO}$ rods}

Ce-doped $\mathrm{ZnO}$ rods have been synthesized by a solvothermal method in a Teflon-lined stainless steel autoclave at $160{ }^{\circ} \mathrm{C}$ for $24 \mathrm{~h}$ using $\mathrm{Zn}(\mathrm{OAc})_{2}$ and $\mathrm{Ce}_{2}\left(\mathrm{SO}_{4}\right)_{3}$ as starting reagents (Scheme 1).

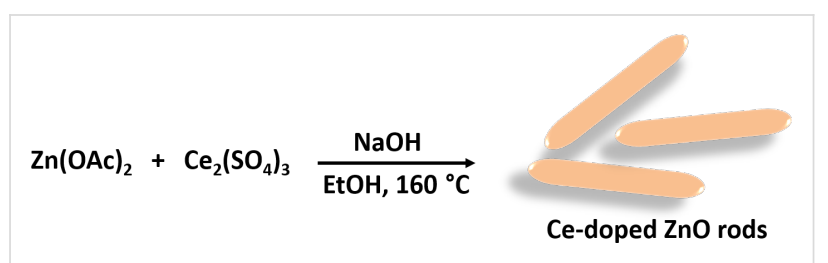

Scheme 1: Schematic illustration of the synthesis of the Ce-doped $\mathrm{ZnO}$ rods.

Figure 1a shows the X-ray diffraction (XRD) patterns of $\mathrm{ZnO}$ rods when varying the Ce-dopant percentage from 0 to 10 . The XRD patterns show sharp peaks, indicating a high degree of crystallinity. The peaks located at $2 \theta$ values of $31.7,34.3,36.1$, $47.5,56.5,62.7,67.8$ and $69^{\circ}$ are ascribed to the (100), (002), (101), (102), (110), (103), (112) and (201) crystal planes of wurtzite $\mathrm{ZnO}$ (JCPDS No 36-1451). It should also be mentioned that for the highest degrees of doping $(5,7$ and $10 \%$ in $\mathrm{Ce}$ doping), an additional and weak signal corresponding to the (111) diffraction plane of cubic $\mathrm{CeO}_{2}$ could be observed at $2 \theta=28.3^{\circ}$ (JCPDS No 34-0394), thus indicating the partial oxidation of $\mathrm{Ce}^{3+}$ into $\mathrm{Ce}^{4+}$ during the synthesis and the formation of $\mathrm{CeO}_{2}$. To demonstrate the incorporation of $\mathrm{Ce}^{3+}$ or $\mathrm{Ce}^{4+}$ in 

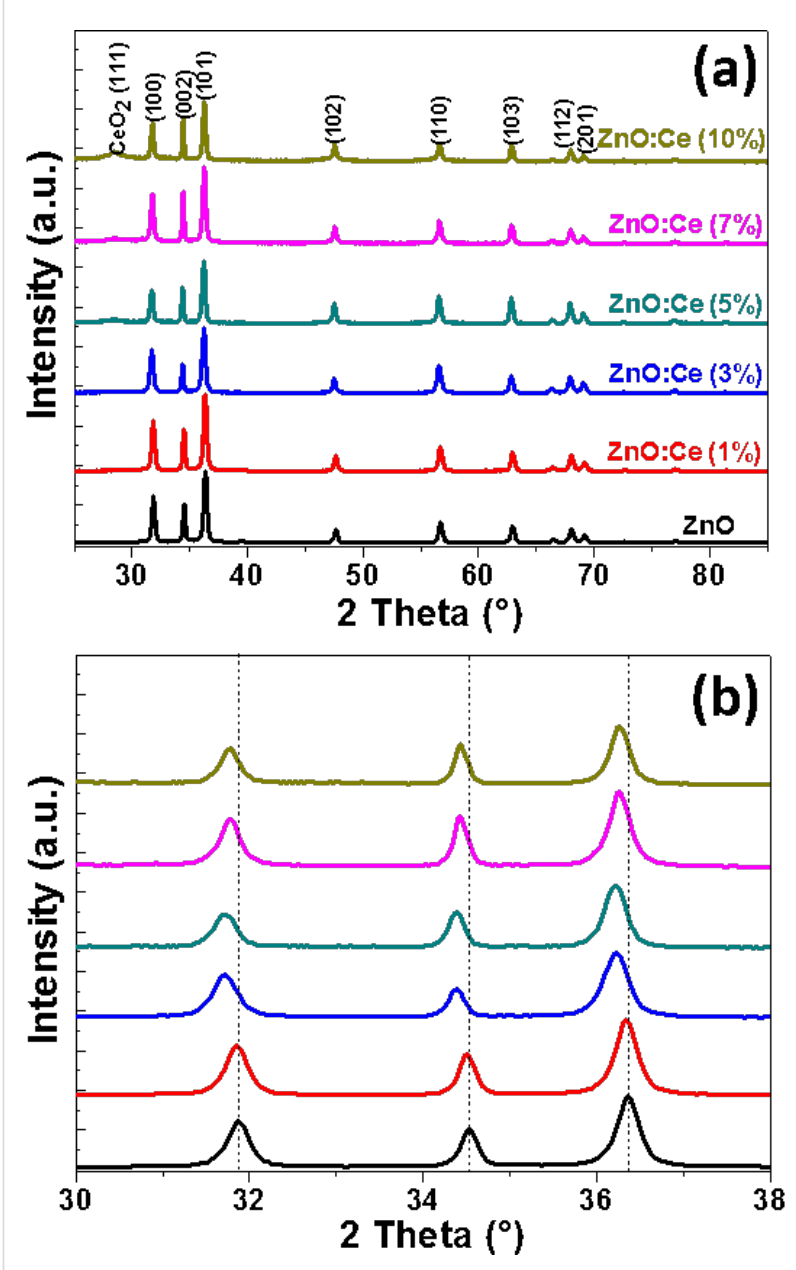

Figure 1: (a) XRD patterns of $\mathrm{ZnO}$ and $\mathrm{Ce}$-doped $\mathrm{ZnO}$ rods and (b) magnification from 30 to $38^{\circ}$.

$\mathrm{Zn}^{2+}$ sites or interstitial sites in the $\mathrm{ZnO}$ lattice, the angle shift of the (100), (002) and (101) peaks as a function of doping percentage has been studied. As can be seen from Figure 1b, the position of these peaks is shifted toward lower angles when increasing the Ce doping, thus indicating its incorporation, at least partly, in the $\mathrm{ZnO}$ crystal lattice [17]. A slight increase of $\mathrm{ZnO}$ a and $\mathrm{c}$ lattice parameters is also observed as a result of the $\mathrm{Ce}$ doping because the radii of $\mathrm{Ce}^{3+}(0.103 \mathrm{~nm})$ and $\mathrm{Ce}^{4+}$ $(0.092 \mathrm{~nm})$ are larger than that of $\mathrm{Zn}^{2+}(0.074 \mathrm{~nm})$ (Table S1 in the Supporting Information File 1). This result is in good accordance with previous reports from the literature [14,34].

The partial oxidation of $\mathrm{Ce}^{3+}$ during the solvothermal synthesis and the formation of $\mathrm{CeO}_{2}$ was further confirmed by Raman spectroscopy and X-ray photoelectron spectroscopy (XPS) analysis. Figure 2 shows the Raman spectra of undoped and Ce-doped $\mathrm{ZnO}$ rods excited by the $532 \mathrm{~nm}$ line of a YAG laser. The peaks located at 332,379 , and $437 \mathrm{~cm}^{-1}$ can be assigned to 2E2, $A 1(T o$ ), and E2(high) vibration modes of wurtzite $\mathrm{ZnO}$

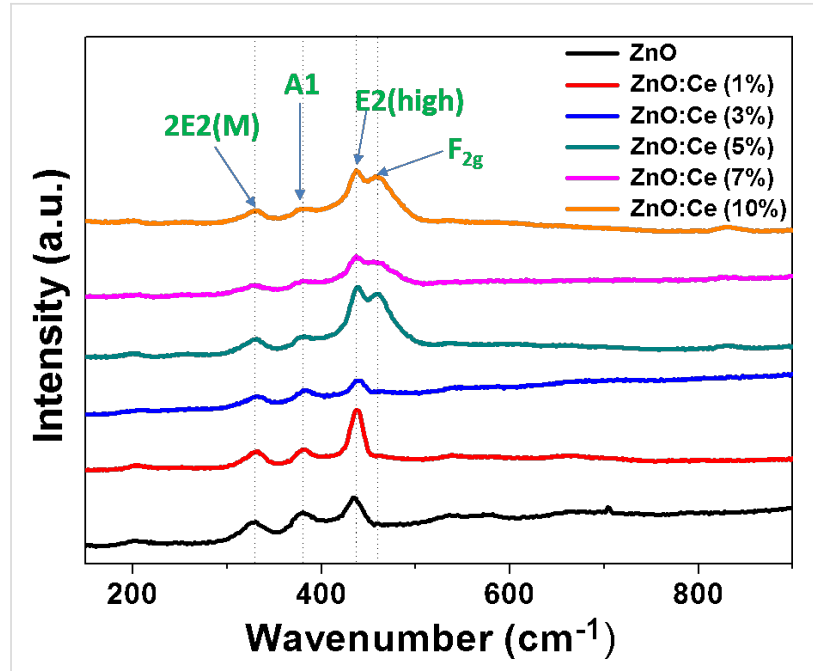

Figure 2: Raman spectra of $\mathrm{ZnO}$ and $\mathrm{ZnO}: \mathrm{Ce}$ rods.

with $P 6_{3} m c$ symmetry [49]. In the spectra of $\mathrm{ZnO}: \mathrm{Ce}(5,7$ and $10 \%$ doping) materials, the signal observed at $457 \mathrm{~cm}^{-1}$ originates from the Raman active mode characteristic of $\mathrm{CeO}_{2}$ fluorite-structured materials with $F 2 g$ symmetry and corresponds to the ceria $\mathrm{Ce}-\mathrm{O} 8$ vibrational unit $[50,51]$.

Further evidence of the presence of $\mathrm{Ce}^{3+}$ and $\mathrm{Ce}^{4+}$ in the materials produced was obtained by XPS analysis. Only the peaks of $\mathrm{Zn} 2 \mathrm{p}, \mathrm{O} 1 \mathrm{~s}$ and Ce $3 \mathrm{~d}$ can be observed on the survey spectrum of the sample doped with $5 \% \mathrm{Ce}$ (Figure $3 \mathrm{a}$ ). The $\mathrm{Zn} 2 \mathrm{p}_{3 / 2}$ peak located at $1021.3 \mathrm{eV}$ is characteristic of $\mathrm{Zn}-\mathrm{O}$ bonds in the $\mathrm{ZnO}$ lattice (Figure $3 \mathrm{~b}$ ). The $\mathrm{O} 1 \mathrm{~s}$ signal could be deconvoluted into three peaks (Figure 3c). The main signal located at $530.2 \mathrm{eV}$ corresponds to $\mathrm{O}$ bound to $\mathrm{Zn}^{2+}$. The low and high energy components located at 529.1 and $532.0 \mathrm{eV}$ can be assigned to $\mathrm{Ce}^{4+}$ and $\mathrm{Ce}^{3+}$ linked to $\mathrm{O}$, respectively. Due to the co-existence of $\mathrm{Ce}^{3+}$ and $\mathrm{Ce}^{4+}$ in $\mathrm{ZnO}: \mathrm{Ce}$ rods, the Ce $3 \mathrm{~d}$ spectrum is complex and shows five doublets originating from the $3 \mathrm{~d}_{5 / 2}$ and $3 \mathrm{~d}_{3 / 2}$ spin-orbit split components (Figure 3d) [52,53]. The energy separations between the two spin-orbit levels were found to be of ca. $18.2 \mathrm{eV}$. The binding energy peaks at 881.0, 885.0, 899.6, and $903.2 \mathrm{eV}$ correspond to $\mathrm{Ce}^{3+}$ species while the peaks at $882.1,888.7,897.9,900.6,907.5$ and $916.3 \mathrm{eV}$ are related to $\mathrm{Ce}^{4+}$ species. It is worth noting that the well separated peak at $916.3 \mathrm{eV}$ is characteristic for the presence of $\mathrm{Ce}(+4)$ in the $\mathrm{ZnO}: \mathrm{Ce}$ rods [53]. Finally, the relative contributions of $\mathrm{Ce}^{4+}$ and $\mathrm{Ce}^{3+}$ states at the surface of $\mathrm{ZnO}$ rods were estimated to be 79 and $21 \%$, respectively.

To evaluate the photo-absorption behaviors of the $\mathrm{ZnO}$ :Ce materials, the UV-visible diffuse reflectance spectra (DRS) were recorded and shown in Figure 4 (undoped $\mathrm{ZnO}$ rods were used as reference). The absorption peak at ca. $370 \mathrm{~nm}$ for $\mathrm{ZnO}$ rods 

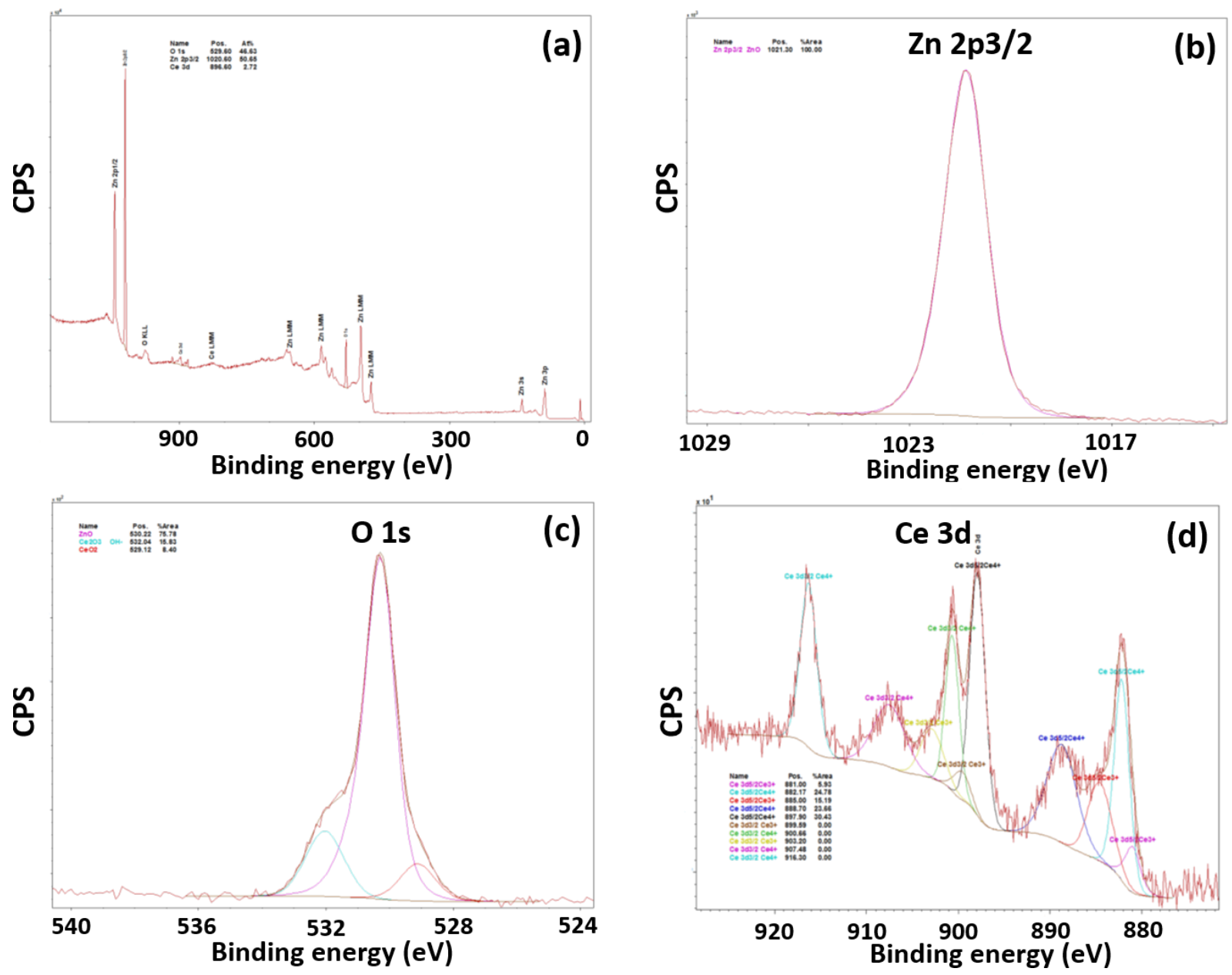

Figure 3: XPS analysis of the prepared $\mathrm{ZnO}: \mathrm{Ce}(5 \%)$ rods. (a) Survey scan, and high resolution scans of (b) $\mathrm{Zn} 2 \mathrm{p}$ region, (c) O $1 \mathrm{~s}$ region, and (d) Ce $3 \mathrm{~d}$ region.

is assigned to the ground excitonic state of $\mathrm{ZnO}$. By comparing the absorptions of $\mathrm{ZnO}$ and Ce-doped $\mathrm{ZnO}$ particles, it can be seen that the absorption intensity of $\mathrm{ZnO}$ :Ce rods in the range of $400-500 \mathrm{~nm}$ is increased with increasing Ce concentrations. The redshift in absorption probably originates from subbandgap transitions originating from Ce doping [34,54]. These electronic transitions from the $\mathrm{VB}$ of $\mathrm{ZnO}$ to the $\mathrm{Ce}$ energy levels require less energy than that of the VB to the $\mathrm{CB}$ of $\mathrm{ZnO}$. Reflectance spectra have been converted to the absorbance spectra using the Kubelka-Munk function $F_{\mathrm{KM}}(R)=(1-R)^{2} / 2 R$, where $R$ is the reflectance recorded for the sample (Figure S1 in the Supporting Information File 1). The bandgap energies determined by an extrapolation method vary between 3.29 and $3.30 \mathrm{eV}$ for $\mathrm{ZnO}$ and $\mathrm{ZnO}$ :Ce rods and indicate that there are quite no changes in the $\mathrm{ZnO}$ bandgap when varying the dopant percentage in $\mathrm{Ce}$, which is in good accordance with absorption results previously described and with a recent report from the literature [34].

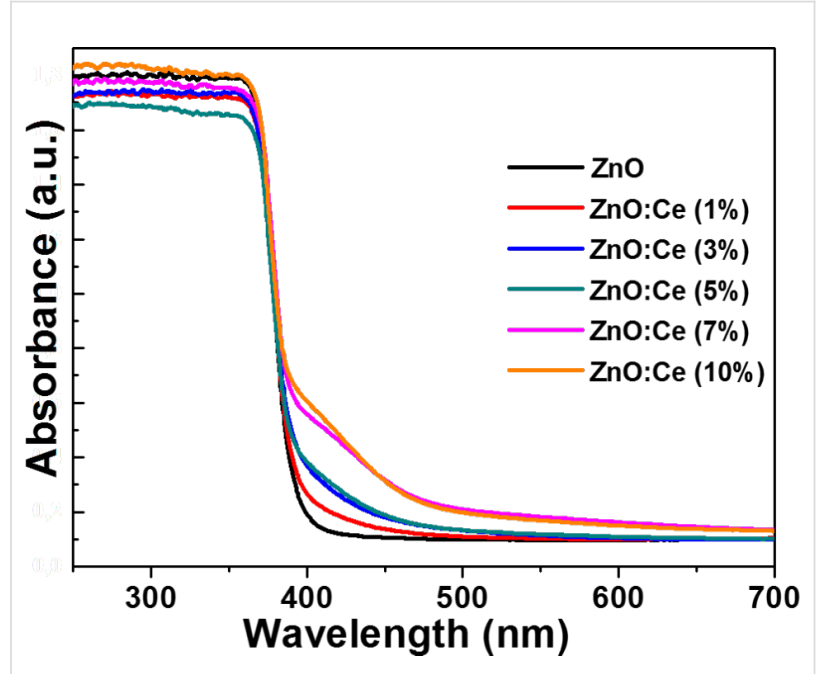

Figure 4: Room temperature UV-visible diffuse reflectance spectra of $\mathrm{ZnO}$ and $\mathrm{Ce}$-doped $\mathrm{ZnO}$ rods. 
Scanning electron microscopy (SEM) images of $\mathrm{ZnO}$ and $\mathrm{ZnO}: \mathrm{Ce}$ particles indicate that all materials are composed of $1 \mathrm{D}$ rod-like ZnO particles of good quality (Figure S2 in the Supporting Information File 1). This was further confirmed by transmission electron microscopy (TEM) experiments (Figure 5). $\mathrm{ZnO}$ rods have a smooth surface, an average length of $130 \mathrm{~nm}$ and a diameter of $23 \mathrm{~nm}$ (Figure 5a). Contrary to hydrothermal methods recently developed for the production of $\mathrm{ZnO}$ :Ce particles [32], the increase in Ce doping does not induce a change in morphology from rods to spheres. An increase in rods length was observed when increasing the Ce doping (ca. $175 \mathrm{~nm}$ for the $10 \%$ doping) and some irregular cylindrical structures developed. The high crystallinity of the particles is further evident from the HRTEM image (Figure 6) and from the selected area electron diffraction (SAED) patterns shown in the insets of Figure 5. The bright and clear diffraction spots belong to the single crystal $\mathrm{ZnO}$ rods. From the HRTEM image (Figure 6a), one can clearly observe the crystal planes of $\mathrm{ZnO}$. The interplanar spacing of $\mathrm{ZnO}$ is of ca. $0.26 \mathrm{~nm}$, corresponding well to the (002) plane of $\mathrm{ZnO}$. For 5, 7 and $10 \%$ doping in $\mathrm{Ce}$, the $\mathrm{ZnO}$ rods were found to coexist with a significantly reduced population of small ellipsoidal $\mathrm{CeO}_{2}$ particles with an average diameter of ca. $5 \mathrm{~nm}$ deposited at the surface of the rods (Figure 6b), forming $\mathrm{CeO}_{2} / \mathrm{ZnO}$ : Ce heterostructures. The analysis of the interplanar distance calculated from the HRTEM image shows the (111) plane of cubic ceria.

The BET surface area of pure $\mathrm{ZnO}$ and 5\% doped $\mathrm{ZnO}: \mathrm{Ce}$ rods were also investigated using nitrogen adsorption-desorption experiments (Figure 7). The $\mathrm{N}_{2}$ adsorption-desorption isotherms are of type II for both materials, according to the
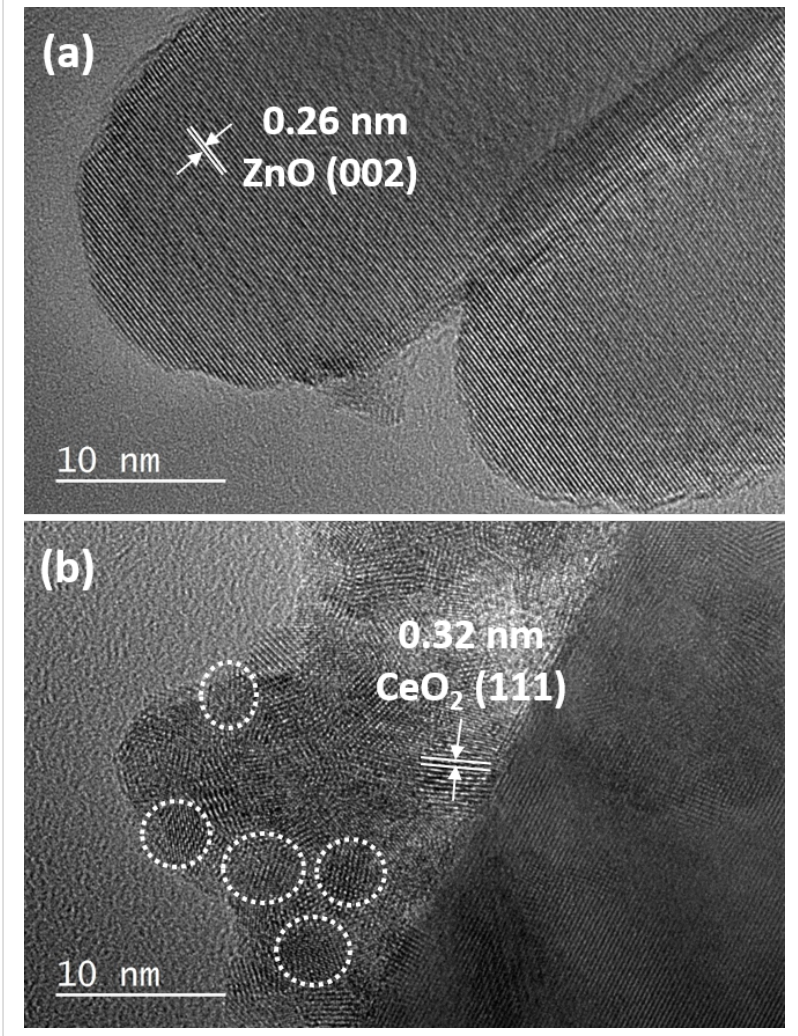

Figure 6: (a) HRTEM image of $5 \%$ Ce-doped $\mathrm{ZnO}$ rods, and (b) TEM image of the $10 \%$ Ce-doped $\mathrm{ZnO}$ rods showing $\mathrm{CeO}_{2}$ nanoparticles at the periphery of the rods.

Brunauer-Dening-Dening-Teller (BDDT) classification [55]. Both materials exhibit high adsorption at relative pressures $P / P_{0}$ close to 1.0, suggesting the formation of large mesopores and
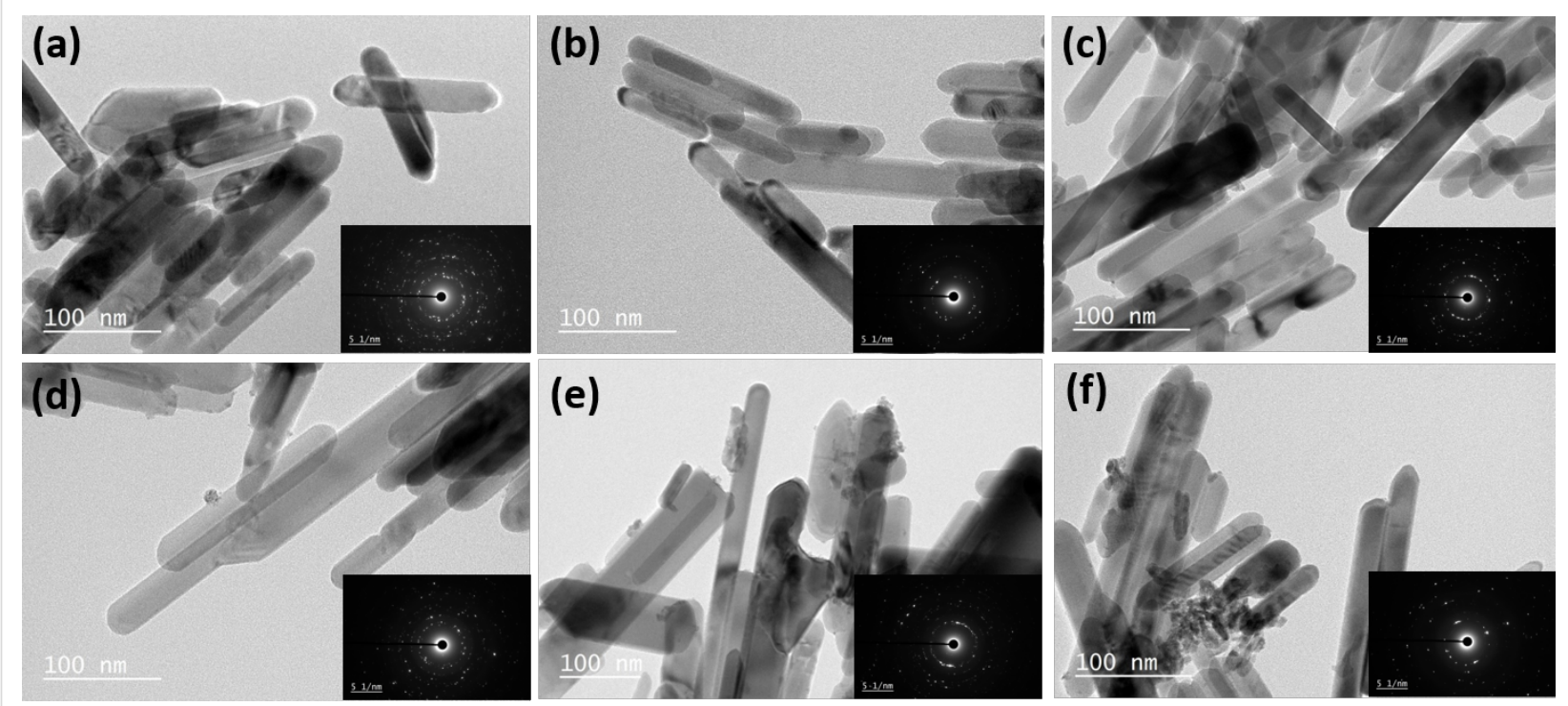

Figure 5: TEM images of (a) ZnO rods and (b-f) $\mathrm{ZnO}$ rods doped with 1, 3, 5, 7 and $10 \% \mathrm{Ce}$, respectively. 

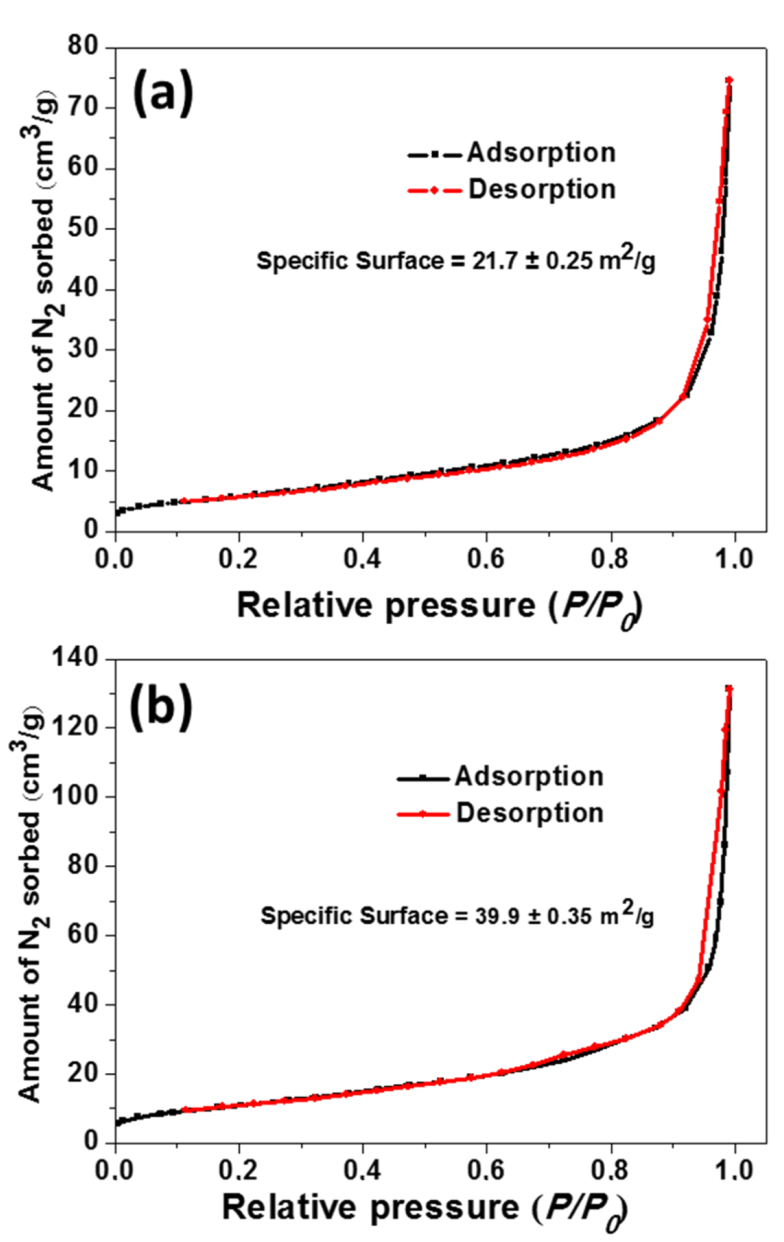

Figure 7: $\mathrm{N}_{2}$ adsorption/desorption curves at $77 \mathrm{~K}$ for $\mathrm{ZnO}$ and $5 \%$-doped $\mathrm{ZnO}$ rods, giving surface areas of 21.7 and $39.9 \mathrm{~m}^{2} / \mathrm{g}$, respectively. Black and red data correspond to the adsorption and desorption branches, respectively.

macropores. The 5\% Ce-doped rods exhibit a higher surface area than $\mathrm{ZnO}$ rods $\left(21.7 \pm 0.2 \mathrm{~m}^{2} / \mathrm{g}\right.$ and $39.9 \pm 0.3 \mathrm{~m}^{2} / \mathrm{g}$ for $\mathrm{ZnO}$ and $\mathrm{ZnO}: \mathrm{Ce}$, respectively). The large specific surface of $\mathrm{Ce}: \mathrm{ZnO}$ rods combined to the ability of the Ce dopant to reduce charge recombinations is promising for the efficient photodegradation of pollutants.

\section{Photocatalytic degradation of Orange II}

We first investigated the photocatalytic activities of Ce-doped $\mathrm{ZnO}$ in comparison to $\mathrm{ZnO}$ rods in the photodegradation of Orange II used at a $10 \mathrm{mg} / \mathrm{L}$ concentration. Initial control experiments showed that (i) solar light irradiation $\left(5 \mathrm{~mW} / \mathrm{cm}^{2}\right)$ in the absence of any photocatalyst does not bleach Orange II and (ii) that the concentration of Orange II remained quite unchanged in the presence of the photocatalyst without light irradiation. As can be seen from Figure 8, under light irradiation, 5, 7 and $10 \%$ Ce-doped $\mathrm{ZnO}$ rods exhibit the highest photocatalytic activity and the degradation is nearly complete after $80 \mathrm{~min}$
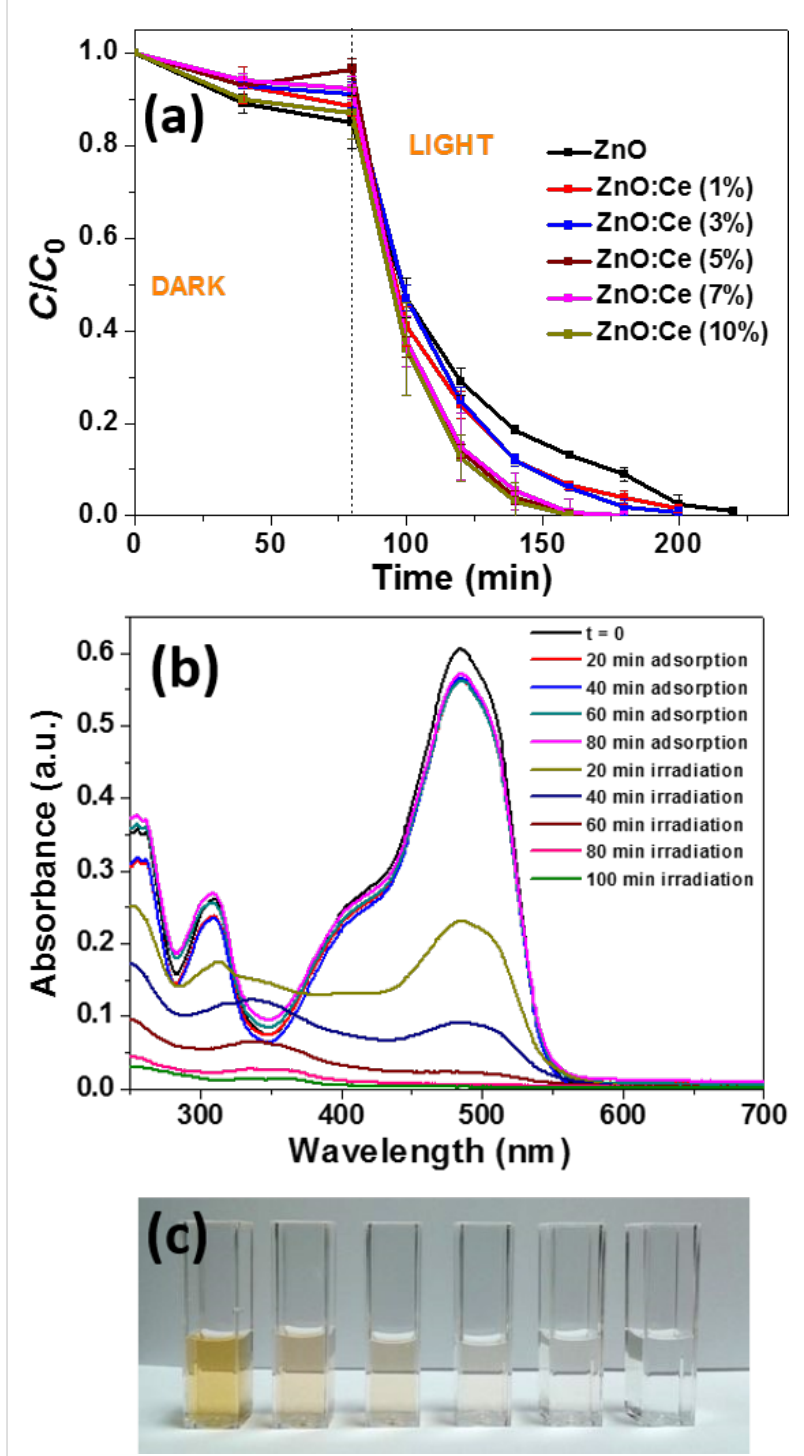

Figure 8: (a) Influence of the doping in $\mathrm{Ce}$ of $\mathrm{ZnO}$ rods for the degradation of Orange II in aqueous solution ( $C$ is the Orange II concentration at time $t$, and $C_{0}$ is the concentration of the dye at $t=0$; Volume of solution, $30 \mathrm{~mL}$; Mass of photocatalyst, $30 \mathrm{mg}$; Orange II concentration, $10 \mathrm{mg} / \mathrm{L}$ ). (b) Variation of Orange II concentration as a function of irradiation time. (c) Photographs of the Orange II solution during photocatalysis.

irradiation. Figure $8 \mathrm{~b}$ shows the decline of the characteristic absorption band of Orange II located at $485 \mathrm{~nm}$ using the $\mathrm{ZnO}: \mathrm{Ce}(5 \%)$ catalyst and demonstrates that the photodegradation is complete (see also Figure $8 \mathrm{c}$ ). The $\ln \left(C / C_{0}\right)$ plots show a linear relationship with the irradiation time, indicating that the photodegradation of Orange II occurs via a pseudo-first-order kinetic reaction $\ln \left(C / C_{0}\right)=-k t$, where $k$ is the photodegradation rate constant $\left(\mathrm{min}^{-1}\right)$ and $C_{0}$ and $C$ are the concentrations of Orange II at time 0 and $t$, respectively. The rate constants $k$ determined for the bleaching of $30 \mathrm{~mL}$ of a $10 \mathrm{mg} / \mathrm{L}$ dye solution were found to be $0.029,0.032,0.039,0.063,0.043$ and 
$0.055 \mathrm{~min}^{-1}$ for $\mathrm{ZnO}$ and $\mathrm{ZnO}$ :Ce rods doped with 1, 3, 5, 7, and $10 \% \mathrm{Ce}$, respectively (see Figure S3 in the Supporting Information File 1 for the plots of $\ln \left(C_{0} / C\right)$ vs reaction time) Based on these results, $\mathrm{ZnO}$ rods doped with $5 \% \mathrm{Ce}$ were used in further experiments.

Because $\mathrm{Ce}: \mathrm{ZnO}$ rods exhibit an extended photoresponding range in the visible region compared to $\mathrm{ZnO}$ (Figure 4), we also evaluated the photodegradation of Orange II under visible light (intensity $=5 \mathrm{~mW} / \mathrm{cm}^{2}$ ) (Figure $\mathrm{S} 4$ in the Supporting Information File 1). Results obtained demonstrate that $78 \%$ of the dye was decomposed after $400 \mathrm{~min}$ and that the photodegradation required a longer time that under solar light irradiation.

\section{Effect of $\mathrm{pH}$ of the Orange II solution}

The influence of the initial $\mathrm{pH}$ value of the Orange II solution on the photocatalytic activity was next studied (all other parameters were kept constant) (Figure 9). The $\mathrm{pH}$ value of the solution was adjusted before the adsorption phase and was not controlled during the reaction course. At $\mathrm{pH}$ values ranging from 4 to 8.5 , no significant differences were observed in the photocatalytic activity. The adsorption of Orange II is increased at $\mathrm{pH} 2$ and the dye bleached in $40 \mathrm{~min}$. $\mathrm{ZnO}$ is known to be of modest stability in acidic medium, slowly dissolves and thus exhibits decreased catalytic activity [56]. The result obtained at $\mathrm{pH} 2$ shows that Ce-doped $\mathrm{ZnO}$ rods exhibit higher stability at low $\mathrm{pH}$ than $\mathrm{ZnO}$. The adsorption of the dye was also slightly increased at $\mathrm{pH} 10$ and 12 and Orange II was decomposed in short times (60 and $40 \mathrm{~min}$ at $\mathrm{pH} 10$ and 12, respectively). The high photocatalytic activity of the Ce-doped $\mathrm{ZnO}$ rods at basic $\mathrm{pH}$ may be attributed to the increased concentration of hydroxy anions that facilitate the photogeneration of hydroxy ${ }^{\circ} \mathrm{OH}$ radicals $\left({ }^{-} \mathrm{OH}+\mathrm{h}^{+} \rightarrow{ }^{\bullet} \mathrm{OH}\right)$, thus enhancing the photocatalytic degradation efficiency.

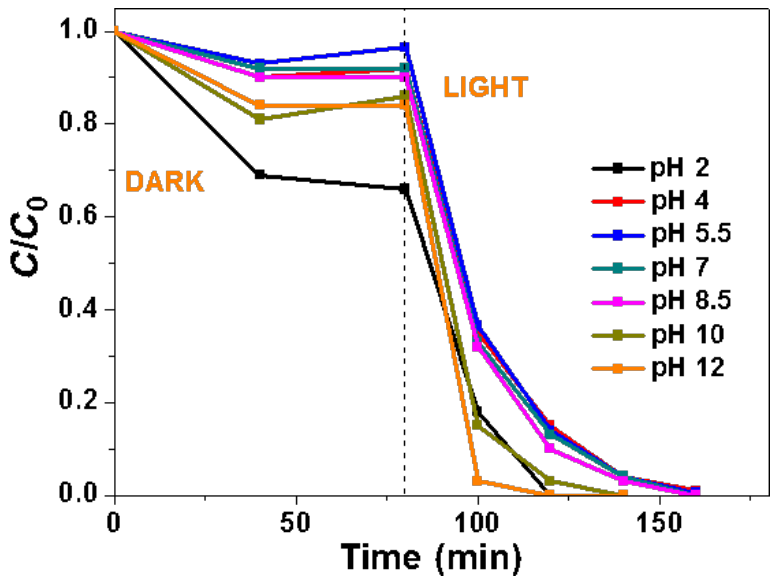

Figure 9: Influence of the $\mathrm{pH}$ of the Orange II solution on the photocatalytic activity of $5 \%$ Ce-doped $\mathrm{ZnO}$ rods.

\section{Effects of Orange II and of the photocatalyst concentrations}

The effect of the mass of photocatalyst used for the degradation of Orange II was first evaluated (Figure 10a). Results obtained show that similar decomposition rates were obtained when using 30 or $45 \mathrm{mg}$ of the catalyst $\left(k=0.063\right.$ and $0.075 \mathrm{~min}^{-1}$, respectively) while the efficiency of the photodegradation decreases when using only $15 \mathrm{mg}$ of the catalyst $\left(k=0.027 \mathrm{~min}^{-1}\right.$ ) (see Figure S5 in the Supporting Information File 1 for the plots of $\ln \left(C_{0} / C\right)$ vs reaction time). The effect of the initial Orange II concentration $(5,10$ or $20 \mathrm{mg} / \mathrm{L})$ on the photodegradation under solar light irradiation was next investigated (Figure 10b). The decomposition rate of the dye was found to decrease with the increase of the dye concentration ( $k=0.1,0.063$ and $0.032 \mathrm{~min}^{-1}$ for Orange II concentrations of 5,10 and $20 \mathrm{mg} / \mathrm{L}$, respectively) (see Figure S6 in the Supporting Information File 1 for the plots of $\ln \left(C_{0} / C\right)$ vs reaction time). This decrease of the catalytic activity when increasing the initial Orange II concentration results from an increased adsorption of the dye on the catalyst surface. In addition, the incident photons may also be absorbed by the Orange II molecules in
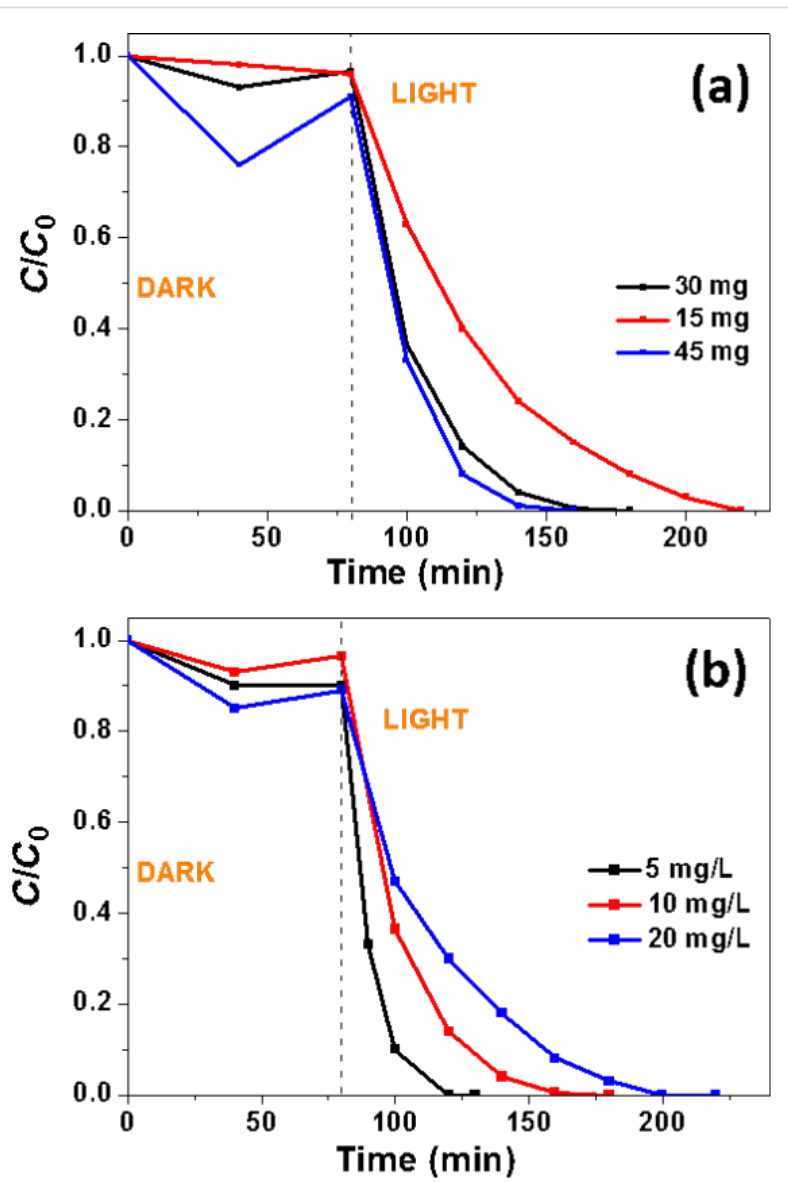

Figure 10: Effects of (a) the catalyst amount and (b) the dye concentration on the photocatalytic activity of $5 \% \mathrm{Ce}$-doped $\mathrm{ZnO}$ rods. 
solution (filter effect), thus decreasing the amount of light available for the production of reactive oxygen species (ROS) at the surface of the photocatalyst.

\section{Influence of salts and molecules on the photocatalytic efficiency}

The performance of $\mathrm{Ce}: \mathrm{ZnO}$ rods for the photodegradation of Orange II in the presence of interfering substances like salts present in wastewater was also investigated. Numerous studies demonstrated that salts do not also adsorb on the photocatalyst surface but may also trap ROS and thus affect the photodegradation rate [57]. In a first set of experiments, we investigated the influence of various chlorides $\left(\mathrm{NaCl}, \mathrm{KCl}, \mathrm{MgCl}_{2}\right.$ and $\mathrm{CaCl}_{2}$ ) used at a $10 \mathrm{mM}$ concentration and at neutral $\mathrm{pH}$ on the photocatalytic activity of $\mathrm{ZnO}: \mathrm{Ce}(5 \%)$ rods (Figure $11 \mathrm{a})$. The amount of dye adsorbed by the photocatalyst and the photocatalytic activity are only slightly influenced by $\mathrm{CaCl}_{2}$ (complete degradation in 100 min while in the absence of $\mathrm{CaCl}_{2}$, the oxidation is complete in $80 \mathrm{~min}$ ). Noteworthy is that $\mathrm{NaCl}$ and $\mathrm{MgCl}_{2}$ increased the photodegradation rate. We assume that $\mathrm{Na}^{+}$or $\mathrm{Mg}^{2+}$ ions can either neutralize the negative sites at the
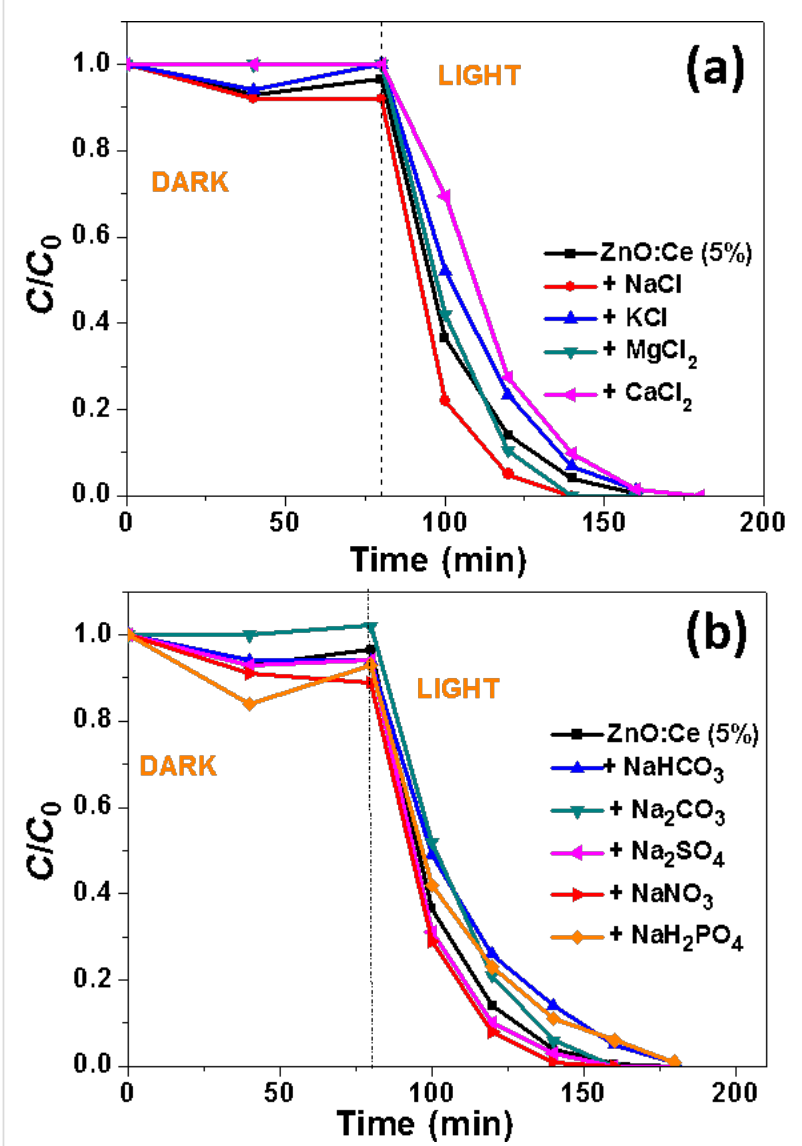

Figure 11: Effects of various salts on the photocatalytic efficiency of the $\mathrm{ZnO}: \mathrm{Ce}$ rods used under solar light irradiation (Volume of solution, $30 \mathrm{~mL}$; Orange II concentration, $10 \mathrm{mg} / \mathrm{L}$; mass of catalyst, $30 \mathrm{mg}$ ). surface of $\mathrm{ZnO}: \mathrm{Ce}$ and thus diminish the electrostatic repulsion of Orange II with the catalyst or that these cations increase the amount of dye at the surface of the catalyst due to electrostatic interactions between the negatively charged Ce-doped $\mathrm{ZnO}$, the cation and the anionic Orange II dye. We also varied the nature of the anions $\left(\mathrm{S}_{2}{ }^{-}, \mathrm{HCO}_{3}{ }^{-}, \mathrm{CO}_{3}{ }^{2-}, \mathrm{SO}_{4}{ }^{2-}, \mathrm{NO}_{3}{ }^{-}\right.$and $\left.\mathrm{H}_{2} \mathrm{PO}_{4}{ }^{-}\right)$ keeping $\mathrm{Na}^{+}$as cation and maintaining the $\mathrm{pH}$ value at 7.0 (Figure 11b). As previously, the influence of these salts on the photocatalytic efficiency was found to be modest and no strong inhibition was observed. These results demonstrate that the $\mathrm{ZnO}$ :Ce photocatalyst is only weakly sensitive to salts commonly present in wastewater. Noteworthy is also that the $\mathrm{Cl}^{-}$and $\mathrm{SO}_{4}{ }^{2-}$ anions, which are well-known to be ${ }^{\circ} \mathrm{OH}$ radicals scavengers, have no detrimental effect on the photocatalytic activity.

Transition metal salts used at $100 \mu \mathrm{M}$ concentration like $\mathrm{ZnCl}_{2}$ or $\mathrm{FeCl}_{3}$ had no influence on the photocatalytic kinetic while $\mathrm{CuCl}_{2}$ and $\mathrm{CoCl}_{2}$ hindered the degradation process probably due (i) to their ability to consume photogenerated $\mathrm{e}^{-}$and (ii) because the reduced cations obtained can trap holes and thus decrease the production of ${ }^{\circ} \mathrm{OH}$ radicals and the reaction rates (Figure 12a) [58]. Glucose, a reducing sugar (100 mg/L), urea $(100 \mathrm{mg} / \mathrm{L})$ or $\mathrm{Na}_{2} \mathrm{~S}(10 \mathrm{mg} / \mathrm{L})$ only slightly decreased the photodegradation rate of Orange II at $\mathrm{pH} 7$ (Figure 12b). Bovine serum albumin (BSA) $(10 \mathrm{mg} / \mathrm{L})$ and aniline $(10 \mathrm{mg} / \mathrm{L})$ had a more pronounced inhibition effect (degradation of Orange II in 120 and $160 \mathrm{~min}$, respectively).

\section{Photocatalyst reusability}

The recycling behavior of $\mathrm{ZnO}$ :Ce rods has also been studied. For this purpose, seven successive photocatalytic experiments were conducted using $30 \mathrm{mg}$ of the same catalyst and by changing the Orange II solution after each cycle. After $1 \mathrm{~h}$ irradiation, the reaction mixture was centrifuged and the UV-visible absorbance of Orange II at $485 \mathrm{~nm}$ measured. The catalyst recovered by centrifugation was reused after a simple washing with water. As can be seen in Figure 13, the photocatalytic activity is retained over $85 \%$ of its original value after five successive runs, which indicates the good stability of $\mathrm{ZnO}: \mathrm{Ce}$ rods. Only after seven cycles, $C / C_{0}$ decreased to ca. 0.65 .

\section{Photocatalytic degradation mechanism}

Scavenging experiments of the active species $\left({ }^{\circ} \mathrm{OH}\right.$ and $\mathrm{O}_{2}{ }^{\cdot-}$ radicals, $\mathrm{e}^{-}$and $\mathrm{h}^{+}$) were conducted to establish the mechanism of the photocatalytic degradation. When $t-\mathrm{BuOH}$, a ${ }^{\circ} \mathrm{OH}$ radical scavenger [59] was added at a $40 \mathrm{~mL} / \mathrm{L}$ concentration, the kinetic of photocatalytic degradation of Orange II was reduced and required ca. 3.4-fold more time compared to the experiment conducted in the absence of $t-\mathrm{BuOH}$ (Figure 14). The strong inhibition of the photodegradation in the presence of $p$-benzoquinone (used at a $2.5 \mathrm{~g} / \mathrm{L}$ concentration) [60], indi- 

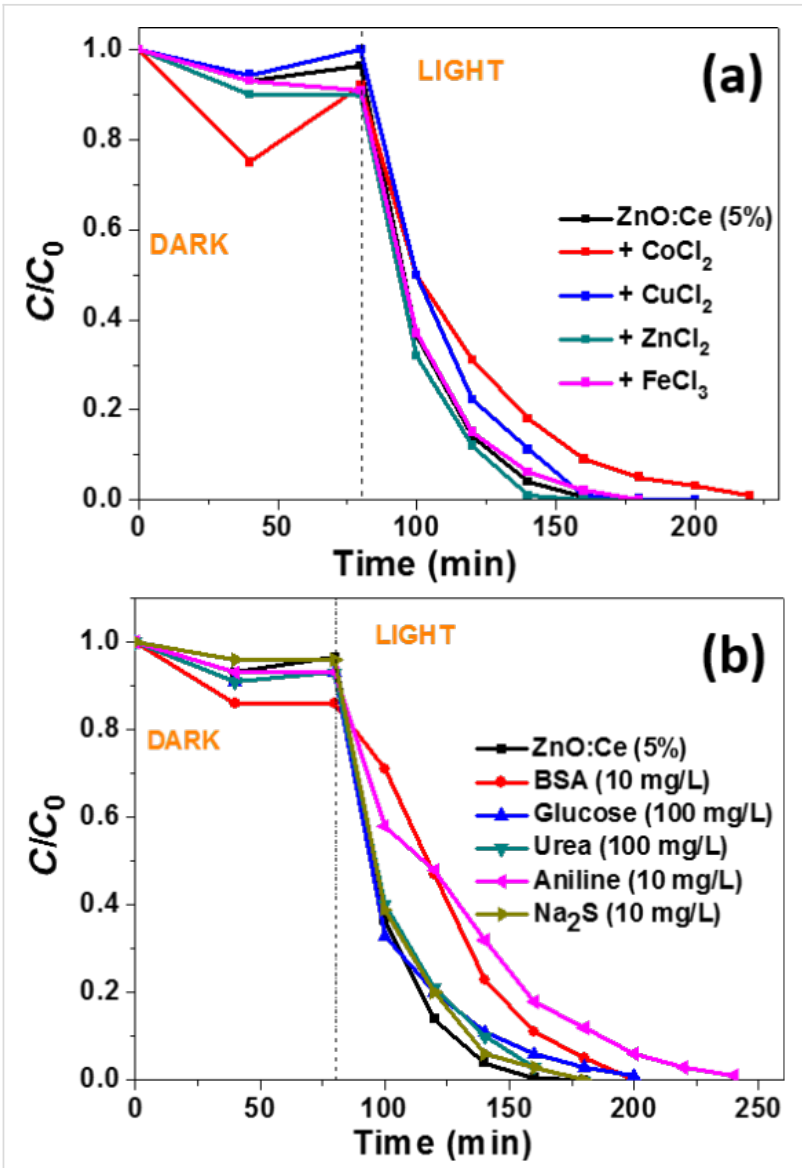

Figure 12: Effects of (a) transition metal salts and (b) of organic compounds and $\mathrm{Na}_{2} \mathrm{~S}$ on the photocatalytic efficiency of the $\mathrm{ZnO}: \mathrm{Ce}$ rods used under solar light irradiation (Volume of solution, $30 \mathrm{~mL}$; Orange II concentration, $10 \mathrm{mg} / \mathrm{L}$; mass of catalyst, $30 \mathrm{mg}$ ).

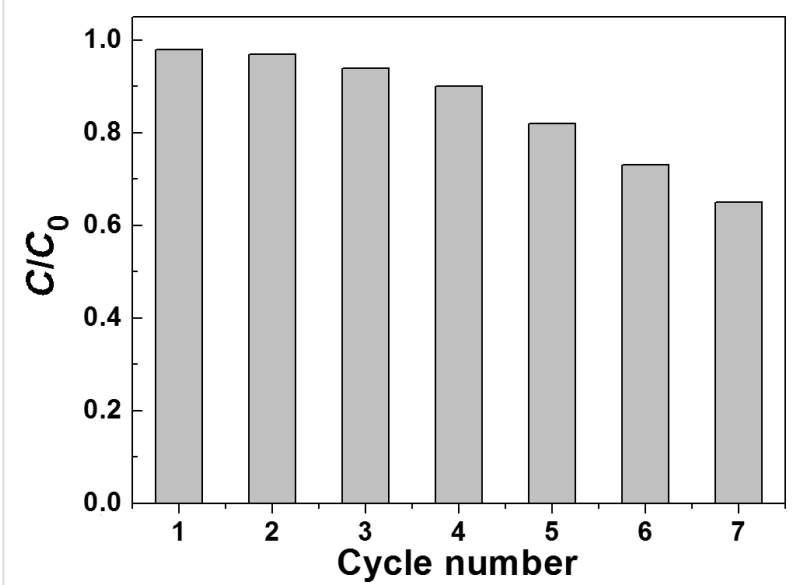

Figure 13: Recyclability of the $\mathrm{ZnO}:$ Ce photocatalyst.

cates that $\mathrm{O}_{2}{ }^{\cdot-}$ radicals (or the species derived like hydroperoxide $\mathrm{HO}_{2}{ }^{\cdot}$ or $\mathrm{H}_{2} \mathrm{O}_{2}$ obtained after reaction with $\mathrm{H}^{+}$) are the major active species in photocatalysis mediated by $\mathrm{ZnO}: \mathrm{Ce}$ rods. Note that there is an overlap at $485 \mathrm{~nm}$ between the UV-visible absorption of Orange II and the oligohydroquinones originating from the $\mathrm{O}_{2}{ }^{--}$-mediated polymerization of $p$-benzoquinone. Finally, the addition of oxalic acid used as $\mathrm{h}^{+}$ scavenger [61] (even used at the high concentration of $20 \mathrm{~g} / \mathrm{L}$ ) influenced less the degradation efficiency than $p$-benzoquinone or $t-\mathrm{BuOH}$, indicating that direct oxidation of Orange II by reaction with $\mathrm{h}^{+}$(Orange $\mathrm{II}+\mathrm{h}^{+} \rightarrow$ Orange $\mathrm{II}^{+}$) has only a modest role in the degradation pathway of the dye.

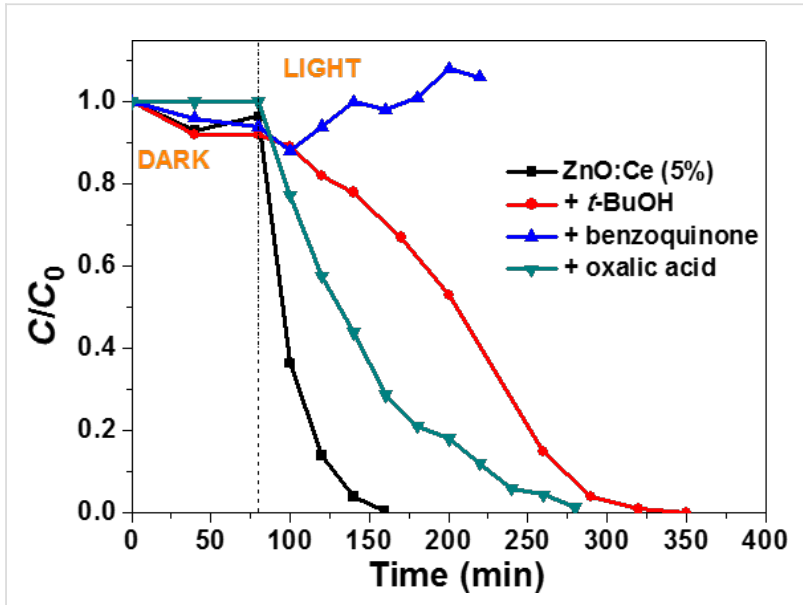

Figure 14: Influence of $t$ - $\mathrm{BuOH}$, benzoquinone and oxalic acid used as $\cdot \mathrm{OH}, \mathrm{O}_{2}{ }^{\cdot-}$ and $\mathrm{h}^{+}$scavengers, respectively, on the photocalytic activity of the $\mathrm{ZnO} / \mathrm{Ce}$ rods.

On the basis of previously described results, the photocatalytic mechanism described in Scheme 2 can be proposed. Under solar or visible light excitation, $\mathrm{e}^{-}$are transferred from the VB to the $\mathrm{CB}$ of $\mathrm{ZnO}$, leaving $\mathrm{h}^{+}$in the VB. Generally, only a weak part of these charge carriers migrates from the core to the surface of particles and reacts with $\mathrm{O}_{2}$ and $\mathrm{H}_{2} \mathrm{O}$. Due to the Ce doping of

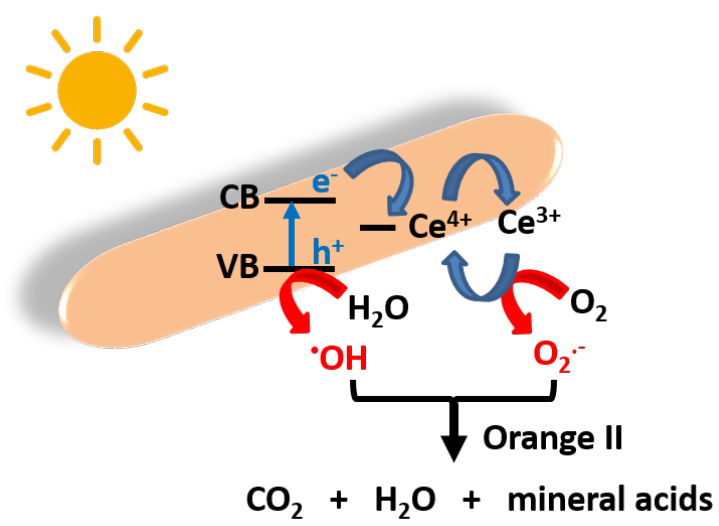

Scheme 2: Schematic representation of the photocatalytic activity of $\mathrm{ZnO}: \mathrm{Ce}$ rods. 
$\mathrm{ZnO}$ rods, the photo-generated $\mathrm{e}^{-}$can transfer to $4 \mathrm{f}$ energetic levels of $\mathrm{Ce}^{4+}$ acting as electron trap, thus decreasing photoinduced $\mathrm{e}^{-} / \mathrm{h}^{+}$recombination. $\mathrm{Ce}^{3+}$ produced after reduction of $\mathrm{Ce}^{4+}$ or $\mathrm{Ce}^{3+}$ ions present in the rods after the solvothermal synthesis can react with dissolved $\mathrm{O}_{2}$ to generate superoxide anions and thus regenerate $\mathrm{Ce}^{4+}$. In the meantime, the $\mathrm{h}^{+}$in the $\mathrm{VB}$ of $\mathrm{ZnO}$ react with $\mathrm{H}_{2} \mathrm{O}$ to produce hydroxyl radicals or with Orange II (direct oxidation pathway). The $\mathrm{O}_{2}{ }^{\cdot-},{ }^{\circ} \mathrm{OH}$ and $\mathrm{h}^{+}$ species oxidize Orange II into $\mathrm{CO}_{2}$, water and mineral acids. Noteworthy is also the presence of mesopores and macropores in the photocatalyst and its relatively high BET surface area which help not only to concentrate the Orange II molecules at the surface of the catalyst but also scatter light between $\mathrm{ZnO}: \mathrm{Ce}$ rods.

\section{Conclusion}

A simple, efficient and cost-effective method to produce Ce-doped $\mathrm{ZnO}$ rods has been developed using a solvothermal method. Ce-doping not only increases the surface area of photocatalysts but also induces a red-shift in the absorption and improves solar and visible light capacities. At the optimal $\mathrm{Ce}$ doping percentage of $5 \mathrm{~mol} \%$, Orange II degradation is complete in $80 \mathrm{~min}$. under solar light irradiation and the $\mathrm{ZnO}: \mathrm{Ce}$ rods exhibit much higher photocatalytic activity than pure $\mathrm{ZnO}$ rods. This high photocatalytic efficiency is associated to the decrease of electron/hole recombination, to the small size of $\mathrm{ZnO}: \mathrm{Ce}$ rods and to their high specific surface compared to $\mathrm{ZnO}$ particles. Furthermore, $\mathrm{ZnO}$ :Ce rods exhibit good stability and can reused at least seven times, thus indicating that these materials have great potential as photocatalysts in practical applications.

\section{Experimental Materials}

$\mathrm{Zn}(\mathrm{OAc})_{2} \cdot 2 \mathrm{H}_{2} \mathrm{O}\left(>98 \%\right.$, Sigma), anhydrous $\mathrm{Ce}_{2}\left(\mathrm{SO}_{4}\right)_{3}(97 \%$, Sigma), Orange II sodium salt ( $>85 \%$, Sigma), sodium hydroxide ( $>97 \%$, Sigma), tert-butanol ( $t-\mathrm{BuOH}, 99 \%$, Sigma), $p$-benzoquinone ( $>98 \%$, Sigma), oxalic acid ( $>99 \%$, Sigma) and anhydrous ethanol were used as received without further purification. All solutions were prepared using Milli-Q water (18.2 $\mathrm{M} \Omega \cdot \mathrm{cm}$, Millipore) as solvent.

\section{Preparation of $\mathrm{ZnO}$ and $\mathrm{ZnO}: \mathrm{Ce}$ nanorods}

In a similar manner as described before [7,13], $\mathrm{ZnO}$ rods were synthesized by a solvothermal method based on the hydrolysis of $\mathrm{Zn}(\mathrm{OAc})_{2}$. Typically, in a three-necked flask equipped with a condenser and a dropping funnel, $\mathrm{Zn}(\mathrm{OAc})_{2} \cdot 2 \mathrm{H}_{2} \mathrm{O}(511 \mathrm{mg}$, $2.33 \mathrm{mmol}$ ) was dissolved in $35 \mathrm{~mL}$ ethanol. To this solution, $\mathrm{NaOH}$ (466 mg, $11.65 \mathrm{mmol}$ ) in $35 \mathrm{~mL}$ ethanol was added dropwise and the mixture was stirred for $30 \mathrm{~min}$ at room temperature. Then, the mixed solution was transferred into a
$140 \mathrm{~mL}$ Teflon-sealed autoclave and was heated at $160{ }^{\circ} \mathrm{C}$ in an electrical oven for $24 \mathrm{~h}$. After allowing to cool naturally, the $\mathrm{ZnO}$ rods were collected by centrifugation, washed three times with water, one time with ethanol, and dried at $70{ }^{\circ} \mathrm{C}$ overnight. Typically, this procedure affords $150 \mathrm{mg}$ of $\mathrm{ZnO}$ rods.

Ce-doped $\mathrm{ZnO}$ rods were prepared using a similar synthetic procedure. For the rods doped with $5 \% \mathrm{Ce}, \mathrm{Zn}(\mathrm{OAc})_{2} \cdot 2 \mathrm{H}_{2} \mathrm{O}$ (485 mg, $2.215 \mathrm{mmol})$ and $\mathrm{Ce}_{2}\left(\mathrm{SO}_{4}\right)_{3}(66.22 \mathrm{mg}, 0.116 \mathrm{mmol})$ were used. The purification and drying procedures are similar to those previously described for $\mathrm{ZnO}$ rods.

\section{Photocatalytic degradation of Orange II}

In a similar manner as described before [7,13], the photocatalytic activity was evaluated by the degradation of an aqueous Orange II solution $(10 \mathrm{mg} / \mathrm{L})$ at room temperature under solar light irradiation. In a typical experiment, the $\mathrm{ZnO}$ :Ce rods (30 mg) were dispersed in $30 \mathrm{~mL}$ Orange II aqueous solution and the suspension was magnetically stirred under ambient conditions for $80 \mathrm{~min}$ in the dark to reach an adsorption-desorption equilibrium. Under stirring, the suspension was exposed to simulated solar light irradiation produced by Sylvania LuxLine FHO T5 neon tubes. The light intensity was controlled using a radiometer (the distance between the lamps and the captors or the surface of the Orange II solution was controlled in each experiment to fix the light intensity at $5 \mathrm{~mW} / \mathrm{cm}^{2}$ ). At various irradiation periods, $1 \mathrm{~mL}$ of the solution was extracted and centrifuged (15000 rpm for $2 \mathrm{~min}$ ) to remove the photocatalyst. The degradation process was monitored by measuring the UV-visible absorption of Orange II at $485 \mathrm{~nm}$. For experiments conducted under visible light irradiation, a polycarbonate filter was used to cut off any light radiation below the wavelength of $400 \mathrm{~nm}$.

\section{Characterization}

TEM images were taken by placing a drop of the particles dispersed in water onto a carbon film-supported copper grid. Samples were studied using a Philips CM200 instrument operating at $200 \mathrm{kV}$. SEM pictures were prepared using JEOL Scanning Electron Microscope JSM-6490 LV. The XRD data were collected from an X'Pert MPD diffractometer (Panalytical AXS) with a goniometer radius $240 \mathrm{~mm}$, fixed divergence slit module ( $1 / 2^{\circ}$ divergence slit, 0.04 rd Sollers slits) and an X'Celerator as a detector. The powder samples were placed on a silicon zerobackground sample holder and the XRD patterns were recorded at room temperature using $\mathrm{Cu} \mathrm{K} \alpha$ radiation $(\lambda=0.15418 \mathrm{~nm})$. XPS analyses were performed on a Gammadata Scienta (Uppsala, Sweden) SES 200-2 spectrometer under ultra-high vacuum $\left(P<10^{-9} \mathrm{mbar}\right)$. The measurements were performed at normal incidence (the sample plane is perpendicular to the emission angle). The spectrometer resolution at the Fermi level 
is about $0.4 \mathrm{eV}$. The depth analyzed extends up to about $8 \mathrm{~nm}$. The monochromatized Al K $\alpha$ source $(1486.6 \mathrm{eV})$ was operated at a power of $420 \mathrm{~W}(30 \mathrm{~mA}$ and $14 \mathrm{kV})$ and the spectra were acquired at a take-off angle of $90^{\circ}$ (angle between the sample surface and photoemission direction). During acquisition, the pass energy was set to $500 \mathrm{eV}$ for wide scans and to $100 \mathrm{eV}$ for high-resolution spectra. CASAXPS software (Casa Software Ltd, Teignmouth, UK, http://www.casaxps.com) was used for all peak fitting procedures and the areas of each component were modified according to classical Scofield sensitivity factors.

The textural properties of the materials were investigated with a Micromeritics 3Flex Surface Characterization Analyzer instrument using liquid nitrogen $\left(-196{ }^{\circ} \mathrm{C}\right)$. Prior to the analyses, the samples were out-gassed overnight under primary vacuum at $40{ }^{\circ} \mathrm{C}$ on the ports of the Micromeritics VacPrep 061 degasser followed by $4 \mathrm{~h}$ out-gassing under high vacuum on the analyse ports. The resulting isotherms were analysed using the BET (Brunauer-Emmett-Teller) method.

All the optical measurements were performed at room temperature $\left(20 \pm 1^{\circ} \mathrm{C}\right)$ under ambient conditions. Absorption spectra of liquid samples were recorded on a Thermo Scientific Evolution 220 UV-visible spectrophotometer. DRS were recorded on a Shimadzu $2600 \mathrm{UV}$-visible spectrophotometer. $\mathrm{BaSO}_{4}$ powder was used as a standard for baseline measurements and spectra were recorded in the range of 250-1400 nm. Raman spectra were recorded using a Xplora spectrometer from Horiba Scientific with $532 \mathrm{~nm}$ wavelength incident YAG laser light.

\section{Supporting Information}

\section{Supporting Information File 1 \\ Additional experimental data. \\ [http://www.beilstein-journals.org/bjnano/content/ supplementary/2190-4286-7-125-S1.pdf]}

\section{References}

1. Fujishima, A.; Honda, K. Nature 1972, 238, 37-38. doi:10.1038/238037a0

2. Li, L.; Liu, X.; Zhang, Y.; Nuhfer, N. T.; Barmak, K.; Salvador, P. A.; Kohrer, G. S. ACS Appl. Mater. Interfaces 2013, 5, 5064-5071. doi:10.1021/am4008837

3. Navaveni, K.; Silvalingam, G.; Edge, M. S.; Madros, G. Environ. Sci. Technol. 2004, 38, 1600-1604. doi:10.1021/es034696i

4. Linsebrigler, A. L.; Lu, G.; Yates, J. T. Chem. Rev. 1995, 95, 735-758. doi:10.1021/cr00035a013

5. Achouri, F.; Corbel, S.; Aboulaich, A.; Balan, L.; Ghrabi, A.; Ben Said, M.; Schneider, R. J. Phys. Chem. Solids 2014, 75, 1081-1087. doi:10.1016/j.jpcs.2014.05.013
6. Dong, S.; Feng, J.; Fan, M.; Pi, Y.; Hu, L.; Han, X.; Liu, M.; Sun, J.; Sun, J. RSC Adv. 2015, 5, 14610-14630. doi:10.1039/C4RA13734E

7. Moussa, H.; Girot, E.; Mozet, K.; Alem, H.; Medjahdi, G.; Schneider, R. Appl. Catal., B: Environ. 2016, 185, 11-21.

doi:10.1016/j.apcatb.2015.12.007

8. Ullah, R.; Dutta, J. J. Hazard. Mater. 2008, 156, 194-200. doi:10.1016/j.jhazmat.2007.12.033

9. Gouvêa, C. A. K.; Wypych, F.; Moraes, S. G.; Durán, N.; Peralta-Zamora, S. Chemosphere 2000, 40, 427-432. doi:10.1016/S0045-6535(99)00312-4

10. Ahmad, M.; Ahmed, E.; Zhang, Y.; Khalid, N. R.; Xu, J.; Ullah, M.; Hong, Z. Curr. Appl. Phys. 2013, 13, 697-704. doi:10.1016/j.cap.2012.11.008

11. Liu, S.; Li, C.; Yu, J.; Xiang, Q. CrystEngComm 2011, 13, 2533-2541. doi:10.1039/c0ce00295j

12. Barick, K. C.; Singh, S.; Aslam, M.; Bahadur, D. Microporous Mesoporous Mater. 2010, 134, 195-202. doi:10.1016/j.micromeso.2010.05.026

13. Achouri, F.; Corbel, S.; Balan, L.; Mozet, K.; Girot, E.; Medjahdi, G.; Ben Said, M.; Ghrabi, A.; Schneider, R. Mater. Des. 2016, 101, 309-316. doi:10.1016/j.matdes.2016.04.015

14. Cheng, B.; Xiao, Y.; Wu, G.; Zhang, L. Appl. Phys. Lett. 2004, 84, 416-418. doi:10.1063/1.1639131

15. Cheng, B. C.; Xiao, Y. H.; Wu, G. S.; Zhang, L. D. Adv. Funct. Mater. 2004, 14, 913-919. doi:10.1002/adfm.200305097

16. Hamadani, N. F.; Mahjoub, A. R.; Khodadadi, A. A.; Mortazavi, Y. Sens. Actuators, B 2012, 169, 67-73. doi:10.1016/j.snb.2012.02.074

17. Yang, J.; Gao, M.; Yang, L.; Zhang, Y.; Lang, J.; Wang, D.; Wang, Y.; Liu, H.; Fan, H. Appl. Surf. Sci. 2008, 255, 2646-2650. doi:10.1016/j.apsusc.2008.08.001

18. Ge, C.; Xie, C.; Cai, S. Mater. Sci. Eng., B 2007, 137, 53-58. doi:10.1016/j.mseb.2006.10.006

19. Li, G.-R.; Lu, X.-H.; Zhao, W.-X.; Su, C.-Y.; Tong, Y.-X. Cryst. Growth Des. 2008, 8, 1276-1281. doi:10.1021/cg7009995

20. George, A.; Sharma, S. K.; Chawla, S.; Malik, M. M.; Qureshi, M. S. J. Alloys Compd. 2011, 509, 5942-5946. doi:10.1016/j.jallcom.2011.03.017

21. Tan, W. K.; Razak, K. A.; Lockman, Z.; Kawamura, G.; Muto, H.; Matsuda, A. Opt. Mater. 2013, 35, 1902-1907. doi:10.1016/j.optmat.2013.01.011

22. Wan, G. X.; Ma, S. Y.; Li, X. B.; Li, F. M.; Bian, H. Q.; Zhang, L. P.; Li, W. Q. Mater. Lett. 2014, 114, 103-106. doi:10.1016/j.matlet.2013.09.094

23. Zhang, Y. G.; Zhang, G. B.; Wang, Y. X. J. Appl. Phys. 2011, 109, 063510. doi:10.1063/1.3561436

24. Lang, J.; Han, Q.; Yang, J.; Li, C.; Yang, L.; Zhang, Y.; Gao, M.; Wang, D.; Cao, J. J. Appl. Phys. 2010, 107, 074302. doi:10.1063/1.3318613

25. Jung, Y.-I.; Noh, B.-Y.; Lu, Y.-S.; Back, S.-H.; Kim, J. H.; Park, I.-K. Nanoscale Res. Lett. 2012, 7, 43. doi:10.1186/1556-276X-7-43

26. Dar, G. N.; Umar, A.; Zaidi, S. A.; Ibrahim, A. A.; Abaker, M.; Baskoutas, S.; Al-Assiri, M. S. Sens. Actuators, B 2012, 173, 72-78. doi:10.1016/j.snb.2012.06.001

27. Sinha, N.; Ray, G.; Bhandari, S.; Godara, S.; Kumar, B. Ceram. Int. 2014, 40, 12337-12342. doi:10.1016/j.ceramint.2014.04.079

28. Karunakaran, C.; Gomathisankar, P.; Manikandan, G. Mater. Chem. Phys. 2010, 123, 585-594. doi:10.1016/j.matchemphys.2010.05.019

29. Faisal, M.; Ismail, A. A.; Ibrahim, A. A.; Bouzid, H.; Al-Sayari, S. A. Chem. Eng. J. 2013, 229, 225-233. doi:10.1016/j.cej.2013.06.004 
30. Djaja, N. F.; Saleh, R. Mater. Sci. Appl. 2013, 4, 245-252. doi:10.4236/msa.2012.34036

31. Yayapao, O.; Thongtem, S.; Phuruangrat, A.; Thongtem, T. Ceram. Int. 2013, 39, S563-S568. doi:10.1016/j.ceramint.2012.10.136

32. Rezaei, M.; Habibi-Yangjeh, A. Appl. Surf. Sci. 2013, 265, 591-596. doi:10.1016/j.apsusc.2012.11.053

33. Liang, Y.; Guo, N.; Li, L.; Li, R.; Ji, G.; Gan, S. RSC Adv. 2015, 5, 59887-59894. doi:10.1039/C5RA08519E

34. Anandan, S.; Miyauchi, M. Phys. Chem. Chem. Phys. 2011, 13, 14937-14945. doi:10.1039/c1cp21514k

35. Subash, B.; Krishnakumar, B.; Velmurugan, R.; Shanti, M. Catal. Sci. Technol. 2012, 2, 2319-2326. doi:10.1039/c2cy20254a

36. Seddigi, Z. S.; Bumajdad, A.; Amsari, S. P.; Ahmed, S. A.; Danish, E. Y.; Yarkandi, N. H.; Ahmed, S. J. Hazard. Mater. 2014, 264, 71-78. doi:10.1016/j.jhazmat.2013.10.070

37. Lam, S.-M.; Sin, J.-C.; Satoshi, I.; Abdullah, A. Z.; Mohamed, A. R. Appl. Catal., A 2014, 471, 126-135. doi:10.1016/j.apcata.2013.12.001

38. Hsu, M.-H.; Chang, C.-J. J. Hazard. Mater. 2014, 278, 444-453. doi:10.1016/j.jhazmat.2014.06.038

39. Fang, J.; Fan, H.; Dong, G. Mater. Lett. 2014, 120, 147-150. doi:10.1016/j.matlet.2014.01.043

40. Rajbongshi, B. M.; Samdarshi, S. K. Mater. Sci. Eng., B 2014, 182, 21-28. doi:10.1016/j.mseb.2013.11.013

41. Khanchandani, S.; Srivestava, P. K.; Kumar, S.; Ghosh, S.; Ganguli, A. K. Inorg. Chem. 2014, 53, 8902-8912. doi:10.1021/ic500518a

42. McLaren, A.; Valdes-Solis, T.; Li, G.; Tsang, S. C. J. Am. Chem. Soc. 2009, 131, 12540-12541. doi:10.1021/ja9052703

43. Zheng, Y.; Chen, C.; Zhan, Y.; Lin, X.; Zheng, Q.; Wei, K.; Zhu, J.; Zhu, Y. Inorg. Chem. 2007, 46, 6675-6682. doi:10.1021/ic062394m

44. Wu, D.; Wang, W.; Tan, F.; Sun, F.; Lu, H.; Qiao, X. RSC Adv. 2013, 3, 20054-20059. doi:10.1039/c3ra42874e

45. Peng, Y.; Qin, S.; Wang, W.-S.; Xu, A.-W. CrystEngComm 2013, 15, 6518-6525. doi:10.1039/c3ce40798e

46. Akhavan, O.; Mehrabian, M.; Mirabbaszadeh, K.; Azimirad, R. J. Phys. D: Appl. Phys. 2009, 42, 225305 doi:10.1088/0022-3727/42/22/225305

47. Baruah, S.; Abbas Mahmood, M.; Zar Myint, M. T.; Bora, T.; Dutta, J. Beilstein J. Nanotechnol. 2010, 1, 14-20. doi:10.3762/bjnano.1.3

48. Qiu, X.; Li, G.; Sun, X.; Li, L.; Fu, X. Nanotechnology 2008, 19, 215703. doi:10.1088/0957-4484/19/21/215703

49. Alim, K. A.; Fonoberov, V. A.; Shamsa, M.; Baladin, A. A. J. Appl. Phys. 2005, 97, 124313. doi:10.1063/1.1944222

50. Shyu, J. Z.; Waber, W. H.; Gandhi, H. S. J. Phys. Chem. 1988, 92, 4964-4970. doi:10.1021/j100328a029

51. Francisco, M. S. P.; Mastelaro, V. R.; Nascente, P. A. P.; Florentino, A. O. J. Phys. Chem. B 2001, 105, 10515-10522. doi:10.1021/jp0109675

52. Burroughs, P.; Hamnett, A.; Orchard, A. F.; Thornton, G. J. Chem. Soc., Dalton Trans. 1976, 1686-1698. doi:10.1039/dt9760001686

53. Pfau, A.; Schierbaum, K. D. Surf. Sci. 1994, 321, 71-80. doi:10.1016/0039-6028(94)90027-2

54. Iqbal, J.; Liu, X.; Zhu, H.; Wu, Z. B.; Zhang, Y.; Yu, D.; Yu, R. Acta Mater. 2009, 57, 4790-4796. doi:10.1016/j.actamat.2009.06.056

55. Singh, K. S. W.; Everett, D. H.; Haul, R. A. W.; Moscou, L.; Pierotti, R. A.; Rouquerol, J.; Siemieniewska, T. Pure Appl. Chem. 1985, 57, 603-619. doi:10.1351/pac198557040603

56. Behnajady, M. A.; Modirshahla, N.; Hamzawi, R. J. Hazard. Mater. 2006, 133, 226-232. doi:10.1016/j.jhazmat.2005.10.022
57. Aghedach, A.; Brosillon, S.; Morvan, J.; Chadi, E. K. J. Hazard. Mater. 2008, 150, 250-256. doi:10.1016/j.jhazmat.2007.04.086

58. Hu, C.; Yu, J. C.; Hao, Z.; Wong, P. K. Appl. Catal., B: Environ. 2003, 46, 35-47. doi:10.1016/S0926-3373(03)00139-5

59. Ou, Y.; Lin, J.-D.; Zou, H.-M.; Liao, D.-W. J. Mol. Catal. A: Chem. 2005, 241, 59-64. doi:10.1016/j.molcata.2005.06.054

60. Yin, M.; Li, Z.; Kou, J.; Zou, Z. Environ. Sci. Technol. 2009, 43, 8361-8366. doi:10.1021/es902011h

61. Kominami, H.; Iwasaki, S.-i.; Maeda, T.; Imamura, K.; Hashimoto, K.; Kera, Y.; Ohtani, B. Chem. Lett. 2009, 38, 410-411. doi:10.1246/cl.2009.410

\section{License and Terms}

This is an Open Access article under the terms of the Creative Commons Attribution License

(http://creativecommons.org/licenses/by/4.0), which permits unrestricted use, distribution, and reproduction in any medium, provided the original work is properly cited.

The license is subject to the Beilstein Journal of

Nanotechnology terms and conditions:

(http://www.beilstein-journals.org/bjnano)

The definitive version of this article is the electronic one which can be found at: doi:10.3762/bjnano.7.125 